\title{
A study on knowledge attitude and practice of contraception in school going children in Wardha district in central India
}

\author{
Manish Jain $^{1}$, Shuchi Jain ${ }^{2}$, Shubhangi Patil ${ }^{1}$, Akash Bang ${ }^{1}$ \\ ${ }^{1}$ Department of Paediatrics, MGIMS, Sevagram, Wardha-442102, Maharashtra, India \\ ${ }^{2}$ Department of Obstetrics \& Gynaecology, MGIMS, Sevagram, Wardha-442102, Maharashtra, India
}

Received: 21 August 2014

Accepted: 19 September 2014

\section{*Correspondence:}

Dr. Manish Jain,

E-mail: manish@mgims.ac.in

Copyright: $\odot$ the author(s), publisher and licensee Medip Academy. This is an open-access article distributed under the terms of the Creative Commons Attribution Non-Commercial License, which permits unrestricted non-commercial use, distribution, and reproduction in any medium, provided the original work is properly cited.

\begin{abstract}
Background: Adolescent sexuality is leading to adolescent pregnancy, unsafe abortion, Reproductive Tract Infections, Sexually transmitted infections. Therefore, studying knowledge, attitude and practice regarding this problem among school adolescents is an essential issue, which can support to overcome young people from sexual related problems.

Methods: This study was cross sectional study conducted in Wardha district of Maharashtra among school going adolescents. Data was collected by the means of anonymous questionnaire after taking the informed consent.

Results: In our study total 375 students were included in the study, amongst 192 were girls and 183 were boys. Majority of students belong to age group of 13-15 years. Nearly 50\% of students were knowing about basic reproductive physiology. Amongst the total 375 participants, $184(49 \%)$ students had ever heard about any of contraceptive method while $51 \%$ of totally unaware. Among total students having knowledge of contraception, $38.7 \%$ knew about condoms, oral contraceptive pills as method of contraception were known to 88 students (23.5\%) while knowledge of emergency contraception was very low. The knowledge of females was higher as compared to males regarding oral and emergency contraception. $15 \%$ of total adolescents accepted that they have used condom. The proportion of males using condoms was higher as compared to females.

Conclusions: The adolescents need to be provided with correct knowledge for behavior change, to stop their undesirable practices for healthy life. There was an evident gap between knowledge and practices with respect to the sexual practices of youth which needs to be bridged.
\end{abstract}

Keywords: Contraception, Adolescent, Knowledge

\section{INTRODUCTION}

\section{Adolescent health}

Adolescence is a fascinating period of life that marks the transition from being dependent child to an independent functioning adult. It is a cross road in life, a time when future directions are determined for better or worse.

Adolescence has been defined by WHO (2003) as a period of 10-19 years of age. ${ }^{1}$

\section{Why adolescents need to be focused?}

They constitute about $21.4 \%$ of the Indian population. ${ }^{2}$ Adolescence is the period of rapid physical growth, sexual and psychological changes. Habits and behavior picked up during adolescence (risk taking behavior, substance abuse, eating habits, conflict resolution) have lifelong impact. Many adolescent boys and girls are sexually active but lack information and skill for selfprotection (low level of information on Family Planning, low contraception use). They have simple but wide 
pervading crucial reproductive health needs - menstrual hygiene, contraception (including emergency contraception) safety from STI and HIV.

They experiences not only physical growth and change but also emotional, psychological, social, and mental change and growth. ${ }^{3}$ Adolescence is a period of increased risk taking and therefore susceptibility to behavioral problems at the time of puberty and new concerns about reproductive health. ${ }^{4}$

\section{Statement of problem}

Adolescent constitute for approximately $1 / 5$ of population with more than $4 / 5$ population in developing countries. ${ }^{5}$ Globally it is understood that consensual activity by adolescents have been exposing them to STIs. More than $50 \%$ of new STIs happen in adolescents. 5 National Family Health Survey (NFHS) ${ }^{6}$ that concluded in 2006 gives us a disturbing figure that $47 \%$ of women aged between 20-24 years were married before they turned 18 years, thus exposing the girls to early sexual activity, early pregnancy and sexually transmitted diseases. $13 \%$ of young women had their sexual debut before 15 years. Study on male sexual debut from Orissa s $36.1 \%$ of urban and $26.3 \%$ rural men had sex before marriage. Youth in India, situation and needs, study (2006-2007) states 2-7\% of young women had engaged in premarital sex, among whom, fewer than $10 \%$ had used condom during previous sexual act. $14.5 \%$ of men from Uttar Pradesh, $13.9 \%$ Bihar, $16.6 \%$ in Jharkhand, $15.5 \%$ in Rajasthan, $16.4 \%$ in Andhra Pradesh had self-reported premarital sexual activity. $^{7}$

Nearly $20 \%$ of the 1.5 million girls married under the age of 15 years are already mothers. Twenty seven percent of married female adolescents have reported unmet needs for contraception. ${ }^{8}$ Over $35 \%$ of all reported HIV/AIDS infections in India occur amongst young people 15-24 years age. ${ }^{9}$

Adolescent sexuality is leading to adolescent pregnancy, unsafe abortion, Reproductive Tract Infections, Sexually transmitted infections, HIV and social problem. Also Lack of "connectedness" with parents and other adults prevents transmission of health messages and crucial skills leading to adoption of risky behavior, substance abuse, early sexual debut and STI, HIV etc.

Therefore, studying knowledge, attitude and practice regarding this sensitive problem among school adolescents is an essential issue, which can support to overcome young people from sexual related problems. It would be thus be reasonable to access the knowledge, attitude and practices of adolescents regarding RTIs, STDs and contraception and then to design program based on findings filling the gaps and spending less time on what teens already know.

\section{METHODS}

\section{Study design}

This is cross sectional study design. (Quantitative method)

\section{Study population}

The study population was high schools in the age group of 10-19 years. from randomly selected four schools of Wardha district.

\section{Sampling}

Four Schools from Wardha city were chosen with the help of random sampling method. Systematic random sampling was used to select participants from the schools. Accordingly 375 students were selected for the study.

\section{Data collection method}

Students from higher secondary schools were included in the study. The necessary permission from school authority was obtained after explaining the objectives of the study. Written informed consent of the parents as well as students was also taken before enrolling the students in the study. The students were informed about the purpose of the study and were assured that their responses would be treated confidentially and will used only for research purposes. Respondents were also informed that their participation was entirely voluntary and that they were free to decline to answer any question that made them feel uncomfortable. The study had ethical clearance from Institutional review board of Mahatma Gandhi institute of medical sciences, Sewagram.

A predesigned, pre-tested, self-administered multiple response questionnaire was provided to the students. Students were well spaced out to avoid communication among them during the exercise. They were also asked to request for clarification if any item in the questionnaire was not clear. Students were not required to identify themselves by writing their names on the questionnaire and confidentiality was emphasized.

Questionnaire included question regarding Sociodemographic characteristics including age, sex, education and occupation of parents, their knowledge, attitudes and practices about contraception and high risk behaviour.

\section{Data entry and analysis}

Data collected was analyzed with the help of SPSS statistical software. Data is represented in the form of frequency tables. 


\section{RESULTS}

\section{Knowledge regarding reproductive physiology}

In the questionnaire, students knowledge regarding the basic reproductive physiology was assessed. Here nearly $50 \%$ of students were having knowledge about the same. Table 1 gives the detailed information in percentage of students having knowledge about particular thing like that of about semen, testosterone, fertilization of ovum and sperm etc. Nearly half of the students were aware that there is possibility of pregnancy if girl does not get her menstrual period in time.

Table 1: Knowledge regarding reproductive physiology.

\begin{tabular}{|c|c|}
\hline \multicolumn{2}{|c|}{ Knowledge level in percentage $(n=375)$} \\
\hline Description & Frequency (percent) \\
\hline \multicolumn{2}{|l|}{ Knowledge about semen } \\
\hline True knowledge & $189(50.2 \%)$ \\
\hline Don't have knowledge & $186(49.8 \%)$ \\
\hline \multicolumn{2}{|c|}{ Knowledge about testosterone } \\
\hline True knowledge & $198(52.8 \%)$ \\
\hline Don't have knowledge & $177(47.2 \%)$ \\
\hline \multicolumn{2}{|c|}{ Knowledge about fertilization of egg } \\
\hline True knowledge & $187(50.8 \%)$ \\
\hline Don't have knowledge & $188(50.2 \%)$ \\
\hline \multicolumn{2}{|c|}{ Relation of menstrual period with pregnancy } \\
\hline True knowledge & $191(50.9 \%)$ \\
\hline Don't have knowledge & $184(50.1 \%)$ \\
\hline \multicolumn{2}{|c|}{ Sperm can live in women's body for some days } \\
\hline True knowledge & $173(46.1 \%)$ \\
\hline Don't have knowledge & $202(53.9 \%)$ \\
\hline
\end{tabular}

\section{Knowledge regarding contraception}

Questionnaire dealt with knowledge of students regarding contraception. Amongst the total 375 participants, 184 $(49 \%)$ students had ever heard about any of contraceptive method while $51 \%$ of totally unaware.

Douching as method of birth control was identified by $42 \%$ of students. Amongst 145 students (38.7\%) knew about condoms, oral contraceptive pills as method of contraception were known to 88 students $(23.5 \%)$ while emergency contraception were known to only $10 \%$ of students. Table 2 depicts knowledge of students about different contraceptive methods.

Amongst the total boys included in the study, $48.9 \%$ were having knowledge about condoms, $24.7 \%$ about oral contraception and $8.2 \%$ about emergency contraception respectively. The percentage of girls having knowledge of condom (51.3\%) and emergency contraception (12\%) was higher than boys. Following Table 3 shows the variation of knowledge of contraception among the girls and boys.
Table 2: Knowledge regarding contraception.

\begin{tabular}{|ll|}
\hline Knowledge regarding contraception & \\
\hline Douching is a method of birth control & $\mathbf{N}=\mathbf{3 7 5}$ \\
\hline True knowledge & $158(42.13 \%)$ \\
\hline Don't have knowledge/false knowledge & $217(57.86 \%)$ \\
\hline $\begin{array}{l}\text { Heard about any of the contraceptive } \\
\text { method }\end{array}$ & $\mathbf{N}=\mathbf{3 7 5}$ \\
\hline Yes & $184(49 \%)$ \\
\hline No & $191(51 \%)$ \\
\hline Knowledge about condom & $\mathbf{N}=\mathbf{3 7 5}$ \\
\hline True Knowledge & $188(50.3 \%)$ \\
\hline Don't have knowledge/false knowledge & $187(49.86 \%)$ \\
\hline $\begin{array}{l}\text { Knowledge about oral contraceptive } \\
\text { pills }\end{array}$ & \\
\hline True knowledge & $88(23.5 \%)$ \\
\hline Don't have knowledge/false knowledge & $287(76.5 \%)$ \\
\hline $\begin{array}{l}\text { Knowledge about emergency } \\
\text { contraception }\end{array}$ & \\
\hline True knowledge & $38(10.1 \%)$ \\
\hline Don't have knowledge/false knowledge & $337(88.9 \%)$ \\
\hline
\end{tabular}

Table 3: Knowledge of girls and boys regarding different contraceptive methods.

\begin{tabular}{|ll|ll|}
$\begin{array}{l}\text { Contraceptive } \\
\text { methods }\end{array}$ & $\begin{array}{l}\text { Male } \\
(\mathrm{n}=183)\end{array}$ & $\begin{array}{l}\text { Female } \\
(\mathrm{n}=192)\end{array}$ & $\begin{array}{l}\text { Total } \\
(\mathrm{n}=375)\end{array}$ \\
\hline Condom & $48.9 \%(94)$ & $51.3 \%(98)$ & $50.3 \%(188)$ \\
\hline $\begin{array}{l}\text { Oral } \\
\text { contraceptive }\end{array}$ & $24.7 \%(45)$ & $22.4 \%(43)$ & $23.5 \%(88)$ \\
\hline $\begin{array}{l}\text { Emergency } \\
\text { contraception }\end{array}$ & $8.2 \%(15)$ & $12 \%(23)$ & $10.1 \%(37)$ \\
\hline
\end{tabular}

When students were asked about combination of condom and spermicide as a method of prevention of STDs as well as pregnancy, $48.3 \%$ of students gave the affirmative answer. The percentage of boys having the knowledge was higher than females. Table 4 depicts the same information in detail.

Table 4: Highly reliable method of preventing pregnancy and STD is to use condom and spermicide.

\begin{tabular}{|llll|}
$\begin{array}{l}\text { Use of condom, } \\
\text { spermicide as } \\
\text { contraceptive } \\
\text { method }\end{array}$ & $\begin{array}{l}\text { Male } \\
(183)\end{array}$ & $\begin{array}{l}\text { Female } \\
(192)\end{array}$ & $\begin{array}{l}\text { Total } \\
(375)\end{array}$ \\
\hline $\begin{array}{l}\text { True knowledge } \\
\text { Don't have }\end{array}$ & $51.1 \%(88)$ & $43.3 \%(83)$ & $48.3 \%(181)$ \\
\hline \begin{tabular}{l} 
knowledge \\
\hline
\end{tabular} & & $56.7 \%(109)$ & $51.7 \%(194)$ \\
\hline
\end{tabular}

\section{Practices}

Among the total 375 students, 56 students (15\%) had used condom as method of contraception. However percentage of boys using condoms was higher than girls. The following Table 5 gives this information this detail. 
Table 5: Use of condoms.

\begin{tabular}{|llll|}
\hline $\begin{array}{l}\text { Used } \\
\text { condom }\end{array}$ & $\begin{array}{l}\text { Male } \\
(\mathbf{N}=183)\end{array}$ & $\begin{array}{l}\text { Female } \\
(\mathbf{N}=192)\end{array}$ & $\begin{array}{l}\text { Total } \\
(375)\end{array}$ \\
\hline Yes & $20 \%(37)$ & $10 \%(19)$ & $15 \%(56)$ \\
\hline No & $80 \%(146)$ & $90 \%(173)$ & $85 \%(319)$ \\
\hline
\end{tabular}

\section{Attitudes}

Regarding the attitude of students about having multiple sexual partners, $55.7 \%$ strongly opposed the tendency of having multiple sexual partners while $44 \%$ believed that it is ok for them to have multiple sexual partners. About $22.7 \%$ believed that sexual intercourse is cool thing while $39.72 \%$ of students believed that girl or boy becomes popular if he has sexual intercourse.

About attitude of students for contraception to be used during intercourse, $58 \%$ have positive attitudes towards usage of condoms during intercourse while $15 \%$ are strongly disagreed for the same. More than half of students $(55.7 \%)$ still are reluctant to discuss the matters regarding sexual issues with their parents or counselors. Following Table 6 gives us detailed information about attitudes of students regarding sexual behavior as well as contraception.

Table 6: Condom should be used while intercourse.

\begin{tabular}{|l|l|}
\hline $\begin{array}{l}\text { Condom should be used at } \\
\text { my age while intercourse }\end{array}$ & $\mathbf{N}=375$ \\
\hline Strongly disagree & $57(15.2)$ \\
\hline Disagree & $98(26.1)$ \\
\hline Agree & $123(32.8)$ \\
\hline Strongly agree & $97(25.9)$ \\
\hline
\end{tabular}

\section{Background characteristics}

The present study being carried out among the students in the age group (10-19 years) in the four randomly selected schools of Wardha. A total of 375 students were included in study. In age group distribution, $62.9 \%$ were in the age group 13-15 years, and $36.4 \%$ were between $15-19$ years. $48.8 \%$ were males while $51.2 \%$ are females. The students mostly belonged to low socioeconomic status. Average literacy rate of parents is low. These factors account for relatively low of knowledge of students regarding their reproductive health as well as and contraception.

\section{DISCUSSION}

\section{Knowledge regarding reproductive physiology}

In the present study, nearly $50 \%$ of students were having knowledge about male sex hormone i.e. testosterone, semen and regarding fertilization. $45.3 \%$ of students were aware that girl may become pregnant after first intercourse. This finding is similar to study done by Mohammad Reza Mohammadi et al. among adolescent where $43.5 \%$ of adolescents were having knowledge about the same. ${ }^{10}$

\section{Knowledge about contraception}

In our study, $50.3 \%$ of students had heard about condom, $23 \%$ about oral contraception and $10 \%$ students had knowledge about emergency contraception. The proportion of males having knowledge of condom is higher than males whereas females were having slightly higher knowledge than males regarding oral contraception. These results are consistent with study by Kotecha et al in urban Vadodara. ${ }^{11}$ In this study $42 \%$ of adolescents were aware of contraceptive methods. Similar results were obtained by Puri et al. ${ }^{12}$ in Chandigarh and Harshal Ruikar. ${ }^{13}$ In Mumbai where $49 \%$ and $41 \%$ of adolescents were aware of contraception respectively.

However knowledge was found to be significantly low among the girls in Udapi taluka of Karnataka. ${ }^{14}$ The reason for this may be regional variation and relatively lack of knowledge among adolescents regarding sexual and reproductive health as difference in study setting.

About $46.7 \%$ of males and $44 \%$ of females were opinion that girls need not to use contraception when she has sex for first time. Amongst the total 375 participants, 184 (49\%) students had ever heard about any of contraceptive method while $51 \%$ of totally unaware. Among total students having knowledge of contraception, $38.7 \%$ knew about condoms, oral contraceptive pills as method of contraception were known to 88 students $(23.5 \%)$ while knowledge of emergency contraception was very low. The knowledge of females was higher as compared to males regarding oral and emergency contraception. Benjamin et al. ${ }^{15}$ in his study found that when the students were asked to list the contraceptive methods they knew, a significantly lower proportion of girls were (47.3\%) knew about condoms, but more girls $(87.3 \%)$ knew about oral contraception. Knowledge of other contraceptive methods in both sexes was very poor. According to study conducted by Kotecha et al. in urban Wadodara $^{11}$ in 2012, about 22 perccent one-third of the boys and one-fourth of the girls had heard about mainly condoms, 11 percent about intrauterine devices and 10 percent about oral pills.

According to study conducted by Dr. Harshal Ruikar ${ }^{13}$ where 279 college going students of slum areas of Mumbai were interviewed. Only $41.2 \%$ of the sampled population had correct knowledge of the contraceptives and $58.8 \%$ had incorrect knowledge.

\section{Practices}

Regarding usage of condoms during intercourse, $15 \%$ of students in the present study accepted that they are using condoms. The percentage was higher in boys as compared to girls. Similar results were obtained by Prateek S. Bobate ${ }^{16}$ in urban slum of Mumbai where 
$24.5 \%$ of adolescents were using condom as method of contraception. In the study by Gottvall et al., ${ }^{17}$ no difference in condom use was observed between girls and boys. In two Swedish studies by Tyden et al. ${ }^{18}$ and by Andersson-Ellström et al., ${ }^{19}$ all surveyed adolescents knew that the use of condoms can protect against the contraction of STDs in general.

This figure is less as compared to usage of condoms in sexually active adolescents of Lao province which was $70 \%$. This is because adolescents engage in sexual activity at relatively young age in developed countries. Also they have higher level of awareness regarding contraception.

\section{Attitudes}

Regarding the attitudes of students about having multiple sexual partners was very casual. Alarmingly $44 \%$ of students were of opinion that its ok to have multiple sexual partners. Significant proportion (39\%) of students also feels that sexual intercourse make them popular.

Similar results were obtained in the study conducted by Marit Hansson et al. ${ }^{20}$ among the students in Semey, Kazakhstan. This implies the proportion of risk our adolescents are exposed to due to their inadequate knowledge and casual attitude.

Nearly half of the students of the students are not comfortable with matters of sexual issues to be discussed with the parents. This is because of social taboo our society possesses regarding sexual issues.

It is interesting to note that poor knowledge and risky practices related to STIs are a universal phenomenon in the young adulthood. While their rights and needs may be acknowledged in theory, in practice they are still confronted with many barriers when it comes to obtaining practical support.

\section{CONCLUSION}

The adolescents are in need to be provided with correct knowledge for behavior change, to stop their undesirable practices and lead them to the road to healthy life. There was an evident gap between knowledge and practices especially with respect to the sexual practices of youth which needs to be bridged. The vicious cycle of problems needs to be broken or else we will lose our prized possession.

Funding: No funding sources Conflict of interest: None declared

Ethical approval: The study was approved by the institutional ethical review board

\section{REFERENCES}

1. World Health Organization. Towards adulthood: exploring the sexual and reproductive health of adolescents in South Asia. In: WHO, eds. WHO Book. New Delhi: World Health Organization; 2003: 1-242.

2. UN Inter Agency Working Group on Population and Development (IAWG-P\&D). Adolescents in India: a profile, 1999-2000. Available at: http://www.bercyproject.org/KBase/WEP/RESOUR CES/adolescentsprofile.pdf.

3. Goldenring J. Puberty and adolescence. A review provided by Veri Med Healthcare Network. Medline plus U.S. national library of medicine. 1995, Available: www.nlm.nih.gov/medlineplus/.

4. UNFPA. Guidelines on reproductive health. New York: United Nations Population Information Network (Popin), 1995. Available at: www.un.org/popin/unfpa/taskforce/guide/iatfreph.gd 1.html.

5. S. Yamuna. Sexually transmitted diseases in adolescents. In: S. Yamuna, eds. Textbook of Pediatric Infectious Diseases. India: Indian Academy of Pediatrics Infectious Diseases; 2005: 507-515.

6. Ministry of Health and Family Welfare. GOI. Reproductive and sexual health of young people in India. Secondary analysis of data from national family health surveys 1, 2 and 3 (1996-2006) for age group of 15-24 years. India: Ministry of health and family welfare. GOI; 2009.

7. IIPS and Population Council, Youth in India. Situation and needs, 2006-2007. In: IIPS, eds. A Report. Mumbai: IIPS, 2010.

8. Office of the Registrar General, Census Commissioner (India). Census of India, 2001. Available at: censusindia.gov.in/2011common/censusdataonline.html.

9. Government of India, New Delhi. National Family Health Survey (NFHS-3) 2005-06. 2007, Available at:

http://cbhidghs.nic.in/writereaddata/linkimages/NFH S-3\%20key\%20Findings5456434051.pdf.

10. Mohammad Reza Mohammadi, Kazem Mohammad, Farideh KA, Farahani, Siamak Alikhani, Mohammad Zare, et al. Reproductive knowledge, attitudes and behaviour among adolescent males in Tehran, Iran. Int Family Planning Persp. 2006,32(1):35-44.

11. P. V. Kotecha, Sangita Patel, R. K. Baxi, V. S. Mazumdar, Shobha Misra, Ekta Modi, et al. Reproductive health awareness among rural school going adolescents of Vadodara district. Indian J Sex Transmit Dis. 2009 Jul-Dec;30(2):94-9.

12. Puri S, Bhatia V, Swami HM, Singh A, Sehgal A, Kaur AP. Awareness of emergency contraception among female college students in Chandigarh, India. Indian J Med Sci. 2007;61:338-46.

13. Ruikar HA. Knowledge, attitude and practices about sexually transmitted infections: a study on 
undergraduate college students of Mumbai. Webmed Central Reprod. 2013;4(3):WMC004166.

14. Rao RS, Lena A, Nair NS, Kamath V, Kamath A. Effectiveness of reproductive health education among rural adolescent girls: a school based intervention study in Udupi Taluka, Karnataka. Indian J Med Sci. 2008 Nov;62(11):439-43.

15. Benjamin AI, Panda P, Singh S, Bhatia AS. Knowledge and attitudes of senior secondary school students of Ludhiana regarding population control and contraception. Indian $\mathbf{J}$ Community Med. 2001;26(4):201-7.

16. Prateek S. Bobhate, Saurabh R. Shrivastava. A cross sectional study of knowledge and practices about reproductive health among female adolescents in an urban slum of Mumbai. J Family Reprod Health. 2001 Dec;5(4):118-24.

17. Gottvall M, Larsson M, Högkund AT, Tydén T. High HPV vaccine acceptance despite low awareness among Swedish upper secondary school students.
Eur J Contracept Reprod Health Care. 2009;14:399405.

18. Tyden T, Norden L, Ruusuvaara L. Swedish students' knowledge of sexually transmitted diseases and their attitudes to the condom. Midwifery. 1991;7:25-30.

19. Andersson-Ellström A, Forssman L. Sexually transmitted diseases: knowledge and attitudes among young people. J Adolesc Health. 1991;12:72-6.

20. Marit Hansson, Leo Stockfelt, Marat Urazalin, Clas Ahlm, Rune Andersson. HIV/AIDS awareness and risk behavior among students in Semey, Kazakhstan: a cross-sectional survey. BMC Int Health Hum Rights. 2008;8:14.

DOI: 10.5455/2320-1770.ijrcog20141206

Cite this article as: Jain M, Jain S, Patil S, Bang A. A study on knowledge attitude and practice of contraception in school going children in Wardha district in central India. Int J Reprod Contracept Obstet Gynecol 2014;3:903-8. 